\title{
La noción de site-specific en el discurso teórico del Teatro da Vertigem ${ }^{1}$
}

The notion of site-specific in the theoretical discourse of the Teatro da Vertigem

\section{Rodrigo Bruna ${ }^{2}$}

Universidad Católica Silva Henríquez

Resumen. En el año 1992 la compañía de Teatro da Vertigem presentó, en una emblemática iglesia de São Paulo, su primera pieza site-specific titulada O Paraíso Perdido. A partir de esta obra la compañía estableció un modelo de trabajo donde la dramaturgia y lo escénico se nutre de las cualidades formales y simbólicas de los lugares que ocupa. En atención a esta premisa nos planteamos las siguientes preguntas: ¿qué tipo de relación teórico-formal establece la compañía Teatro da Vertigem con la noción site-specific? ¿qué puntos de encuentro se pueden evidenciar entre las artes visuales y escénicas a partir de las particularidades específicas de un lugar? Para dar respuesta a estas preguntas, establecimos una metodología de trabajo centrada en el análisis crítico de documentos, registros audiovisuales e imágenes, acciones que nos permitieron situar el problema con el fin de comprender el discurso teórico de esta compañía.

Palabras clave. Site-specific, Teatro da Vertigem, Artes Escénicas, Artes Visuales.

\begin{abstract}
In 1992 the Teatro da Vertigem company presented, at an emblematic church in São Paulo, its first site-specific piece entitled $O$ Paraiso Perdido. From this work the company established a working model where the dramaturgy and the scenic is nourished by the formal and symbolic qualities of the places it occupies. Keeping with this premise, we ask ourselves the following questions: what kind of theoretical-formal relationship does the Teatro da Vertigem company establish with the site-specific notion? What meeting points can be seen between the visual and performing arts based on the specific characteristics of a place? To answer these questions, we established a work methodology focused on the critical analysis of documents, audiovisual records and images, actions that allowed us to locate the problem in order to understand the theoretical discourse of this company.
\end{abstract}

Keywords. Site-specific, Teatro da Vertigem, Performing Arts, Visual Arts.

\footnotetext{
${ }^{1}$ Investigación financiada en el marco de la Beca Doctorado Nacional, Agencia Nacional de Investigación y Desarrollo Chile ANID.

${ }^{2}$ Doctor en Artes mención Artes Visuales, Pontificia Universidad Católica de Chile. Doctor en Historia de Arte, Universitat Autònoma de Barcelona (cotutela internacional). Actualmente es académico en la Escuela de Educación Artística, Universidad Católica Silva Henríquez y en el Departamento de Teatro, Universidad de Chile. Email: rbruna@ucsh.cl
} 


\section{Introducción}

El año 1992 la compañía paulista Teatro da Vertigem presentó la obra O Paraíso Perdido en la Iglesia Santa Ifigenia de São Paulo, este hecho marcó el inicio de un trabajo investigativo donde la dramaturgia se vio tensionada por las particularidades que brindan los espacios escogidos. Como resultado de lo anterior Antônio Araújo, director de la compañía, asumió la noción de site-specific para definir la práctica escénica desempeñada por la compañía. Dicha práctica está fundada en una dramaturgia colaborativa que recoge las cualidades formales y simbólicas de los lugares elegidos y ocupados.

En atención a esta premisa, nos planteamos las siguientes preguntas: ¿qué tipo de relación teórico-formal establece la compañía Teatro da Vertigem con la noción site specific? ¿qué puntos de encuentro se pueden evidenciar entre las artes visuales y escénicas a partir de las particularidades específicas de un lugar? A través de estas preguntas establecemos como principal objetivo comprender la noción de site-specific presente en el discurso teatral propuesto por la compañía de Araújo. A partir de este objetivo, buscamos definir y contextualizar el problema con el fin de generar puntos de encuentro que nos permitan comprender el discurso teórico de la compañía paulista. Para dar cuenta de este objetivo, el estudio estableció una metodología de trabajo centrada en el análisis crítico de documentos, registros audiovisuales e imágenes, labor que permitió situar y analizar el problema en cuestión.

En conformidad a lo expuesto estructuramos el presente artículo en cuatro apartados. En primer lugar, abordaremos los aspectos esenciales del discurso teórico y práctico de la compañía Teatro da Vertigem. En segundo lugar, analizaremos la noción de site-specific en el campo de las artes visuales y a partir de las obras de Robert Smithson, Daniel Buren y Christian Boltanski. En tercer lugar, indagaremos en los vínculos existentes entre la noción de site specific y las artes escénicas a la luz de los planteamientos teóricos de Richard Schechner y Hans-Thies Lehmann. Finalmente, y a modo de conclusión sintetizaremos los aportes del texto con el fin de comprender el discurso teórico propuesto por la compañía de Antônio Araújo.

\section{El Teatro da Vertigem}

El Teatro Da Vertigem aparece en escena el año 1991 como un grupo de investigación formado por egresados de la Escuela de Comunicación y Artes de la Universidad de São Paulo. El grupo es liderado por el director y dramaturgo Antônio Araújo quien, a través de su trabajo con la compañía, ha fomentado una práctica investigativa que se funda en una dramaturgia colaborativa. En atención a la propuesta de Araújo la investigadora Silvana García señala:

$\mathrm{Su}$ proceso de trabajo es también uno de los pocos a los cuales podemos aplicar el calificativo de "colectivo". Construye el espectáculo en procesos y en complicidad con un elenco que, como él, se entrega totalmente al trabajo durante largos períodos. El texto va siendo construido sobre la marcha, por medio de talleres en los cuales los 
actores improvisan sobre diferentes temas, acompañados de un dramaturgo que da forma y firma la dramaturgia final. (García, párr. 2).

Esta condición colectiva se transformó en una práctica colaborativa, que es entendida en voz de Antonio Araújo desde una horizontalidad, donde las jerarquías se diluyen en un espacio de creación, en el que actor, escenógrafo, dramaturgo y director conforman una unidad. Dicha unidad se potencia en un proceso de obra que se sustenta en el diálogo y la negociación, donde la autoría se entiende como un hecho compartido por todos y todas (Araújo 222).

El trabajo colaborativo es el sello distintivo que caracteriza el proceso de creación que desarrolla el Teatro da Vertigem, instancia que se complementa y potencia con el encuentro con la ciudad, espacio que se transforma en un eje articulador que permite a la compañía situar su práctica artística y reflexiva. En este sentido podemos afirmar que la ciudad otorga a la compañía lugares impregnados de una carga simbólica dada por historias y memorias silenciadas. Al respecto Silvana García señala: "pasear por un hospital vacío lleno de ecos y residuos de existencias pasadas, ya nos impone otro modo de andar y mirar, más lento, más reflexivo.” (38).

Asimismo, podemos señalar que los temas abordados por la compañía surgen del propio material que los lugares otorgan: “[...]el significado simbólico, histórico, político e institucional del lugar es más importante que sus posibilidades escénico-arquitectónicas” (Araújo 220). Son finalmente lugares que posibilitan un diálogo que amplía críticamente los procesos de construcción dramática desde una mirada que pone en valor las cualidades del espacio. Al respecto, podemos afirmar que la dramaturgia elaborada por la compañía no solo se hace cargo de la arquitectura del lugar, sino también de la carga semántica que estos espacios ostentan. En este sentido la obra $O$ Paraíso Perdido $(1992)^{3}$ es un buen ejemplo para hacer patente este vínculo simbólico con el lugar (figura 1).

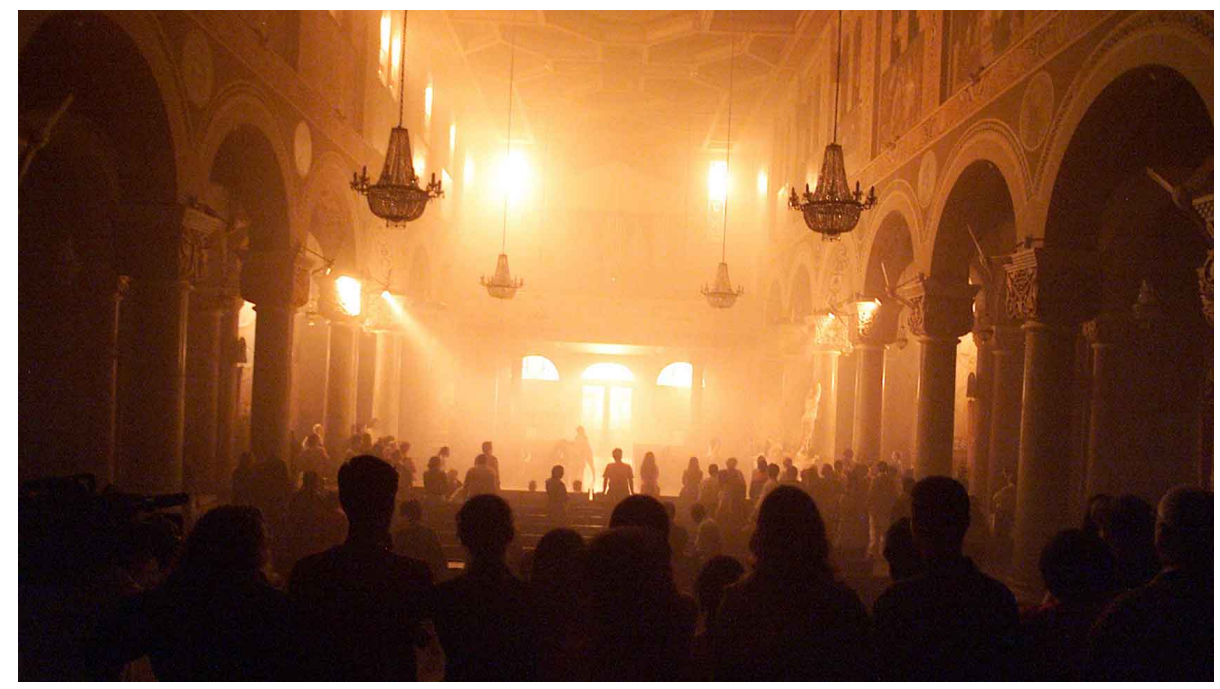

${ }^{3}$ O Paraíso Perdido es la primera obra de la compañía Teatro da Vertigem y se realizó en la iglesia católica de Santa Ifigenia de Sao Paulo. La pieza se basa principalmente en el poema narrativo de John Milton titulado El Paraíso Perdido (1667), obra que aborda el tema bíblico de Adán y Eva a partir de una reflexión contemporánea que se centra en la existencia del bien y el mal. 
Fig. 1. Teatro da Vertigem, O Paraíso Perdido, 1992. Registro fotográfico de la obra, Iglesia Santa Ifigenia, São Paulo, Brasil. Fuente imagen: https://www.teatrodavertigem.com.br/o-paraiso-perdido

A partir de esta obra evidenciamos la relación existente entre las referencias literarias, los elementos espaciales y objetuales presentes en el lugar: "Los actores utilizaban todo el espacio del templo, desplazando el mobiliario, abriendo o cerrando áreas de juego y conduciendo con sus cantos al público en torno de altares y confesionarios" (García 30).

Sobre el particular podemos señalar que el espacio escogido interpela a la dramaturgia haciendo que esta sea "reescrita y adaptada a las condiciones arquitectónicas específicas" (Araújo 220). La elección de un lugar semánticamente fuerte, como es una iglesia, toma sentido en la medida que se transforma en un aporte al trabajo dramatúrgico y escénico de la compañía.

En igual sentido, podemos mencionar la obra Dido e Enéas (2008) opera cuya puesta en escena se realizó en el Centro de Producción del Teatro Municipal de São Paulo. Este espacio de almacenaje y producción de escenarios, vestuario y utilería, se trasformó en el escenario para la opera de Henry Purcell ${ }^{4}$. La pieza no se desarrolla en un espacio construido (ficción) sino en un espacio dado (realidad) como es una bodega. Tarimas, andamios, vehículos, restos de materiales y herramientas diversas se transformaron en recursos escénicos en el marco de una obra que relee la alegoría barroca de Purcell. Del mismo modo, podemos afirmar que esta relectura cuestiona no solo la ficción del propio género de la ópera, sino también la concepción de un espacio escénico definido por los roles que cumplen actores y espectadores (figura 2).

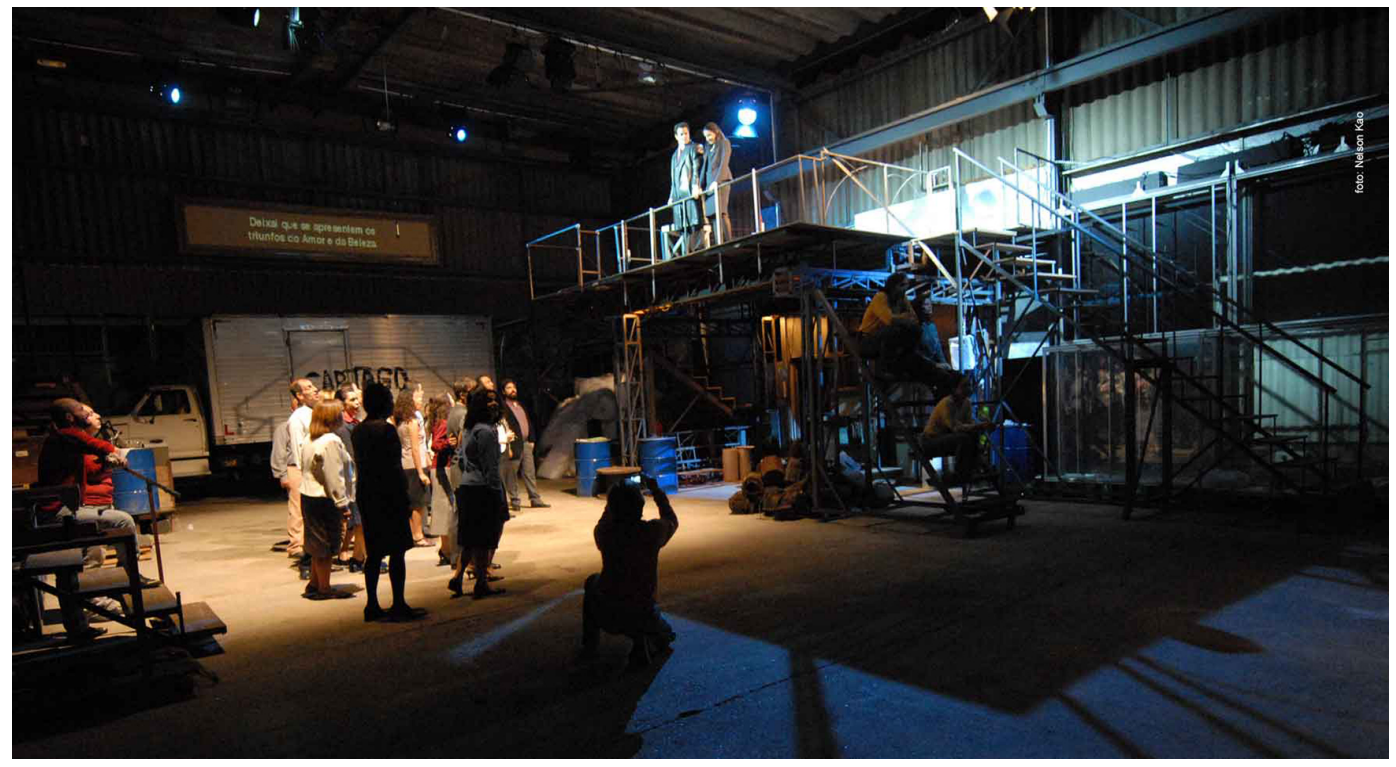

Fig. 2. Teatro da Vertigem, Dido y Enéas, 2008. Registro fotográfico de la obra, Centro de Producción, São Paulo, Brasil. Fuente imagen: https://www.teatrodavertigem.com.br/dido-e-eneas

\footnotetext{
${ }^{4}$ Henry Purcell crea la obra Dido y Eneas en 1687 junto al dramaturgo Nahum Tate. La opera narra la historia de amor trágica acontecida entre Dido, la Reina de Cartago y el Eneas héroe troyano.
} 


\section{Site-specific y Artes Visuales}

La noción site specific surge en el campo de las artes visuales a fines de la década de los sesenta y en el contexto de las prácticas conceptuales. En una primera aproximación al concepto, Miwon Kwon nos señala: "[el] trabajo de sitio específico en su formación temprana, estaba centrado en establecer una relación confusa e indivisible entre la obra y su lugar, y demanda la presencia física del espectador para completar el trabajo." (Kwon 11-12) . Obra y lugar se ven activados por la presencia de un espectador que decodifica y se apropia de una experiencia que apela a todos los sentidos fuera del espacio institucional del museo.

Estas primeras experiencias responden al trabajo realizado por los artistas del Land Art como Michael Heizer y Robert Smithson. Este último creó en 1970 Partially Buried Woodshed obra emplazada en los alrededores de Kent State University, que consistió en cubrir con tierra y escombros una caseta de almacenamiento de leña. Smithson, a partir de este ejemplo, entiende sus obras no como elementos aislados sino como elementos integrados al entorno, que relevan la importancia del lugar, del sitio. El historiador del arte Javier Maderuelo en atención a la obra de Smithson afirma:

El "Site" es el lugar concreto sobre el que Robert Smithson se detiene para trabajar, mientras que el "Nonsite" es la "obra" expuesta en la galería, que suele consistir en arcones con formas marcadamente geométricas, de fabricación industrial, que contiene muestras de materiales extraídos en el "Site" acompañados con imágenes fotográficas. (173).

Como una forma de ampliar las nociones de "Site" y "Nonsite", Smithson establece la noción de no-espacio para referirse a aquellos lugares sin identidad como las autopistas, las multitiendas, las gasolineras, los aeropuertos, etc. Estos no-espacios se relacionan con los nolugares analizados por Marc Augé: "Si un lugar puede definirse como lugar de identidad, relacional e histórico, un espacio que no puede definirse ni como espacio de identidad ni como relacional ni como histórico, definirá un no-lugar" (Augé 83). Es desde esta distinción entre "lugar" y "no lugar" que la práctica del site-specific integra el paisaje, la ciudad y los objetos.

En relación a lo comentado por los autores ya citados, resulta pertinente hacerse cargo de un concepto que tensiona la noción site-specific, nos referimos al termino in situ. Esta palabra proviene del latín «en el sitio», «en el lugar» e identifica aquellas acciones realizadas para un lugar específico, las que entran en vínculo con el contexto que las acoge, vale decir, son acciones regidas por un aquí y un ahora que determinan su condición temporal y espacial. Importante de destacar es el hecho que la expresión in situ no es solo utilizada en el campo de las artes visuales

\footnotetext{
${ }^{5}$ La traducción de la cita es mía: Site-specific work in its earliest formation, then focused on establishing and inextricable, indivisible relationship between the work and its site, and demanded the physical presence of the viewer for the work's completion.
} 
sino también en el ámbito de la arquitectura y la arqueología. En este sentido, la noción site specific presenta un uso más particularizado en el campo de las artes visuales.

Caso emblemático en el uso de la palabra in situ es el artista francés Daniel Buren (n.1938), quien ha sido enfático en catalogar su obra como travail in situ y no como obras sitespecific, decisión que se podría interpretar como un gesto de autoría que inscribe una práctica al interior del campo de las artes visuales. Los travail in situ son obras pensadas para lugares específicos, que consideran las cualidades arquitectónicas, simbólicas y culturales de un lugar. Ejemplo paradigmático de esta práctica es Les deux Plateaux la pieza realizada en 1986 por Buren y emplazada en el Palais Royal de París. En el patio del palacio, el artista francés instaló 260 columnas octogonales fabricadas con franjas de mármol blanco y negro, que cubren una superficie de 3.000 metros cuadrados. Las columnas emergen desde el suelo, a distintas alturas y a partir de una distribución simétrica que asemeja un tablero de ajedrez. El conjunto fue pensado para ese lugar, en consideración a sus cualidades arquitectónicas y simbólicas. Las columnas de Buren repican la forma y distribución racional de las propias columnatas que rodean el patio, estableciendo una simbiosis formal y estética que actualizan la tradición clásica. Las columnas emergen del subsuelo y se alzan al cielo como sostén de la propia institucionalidad política y cultura francesa (figura 3).

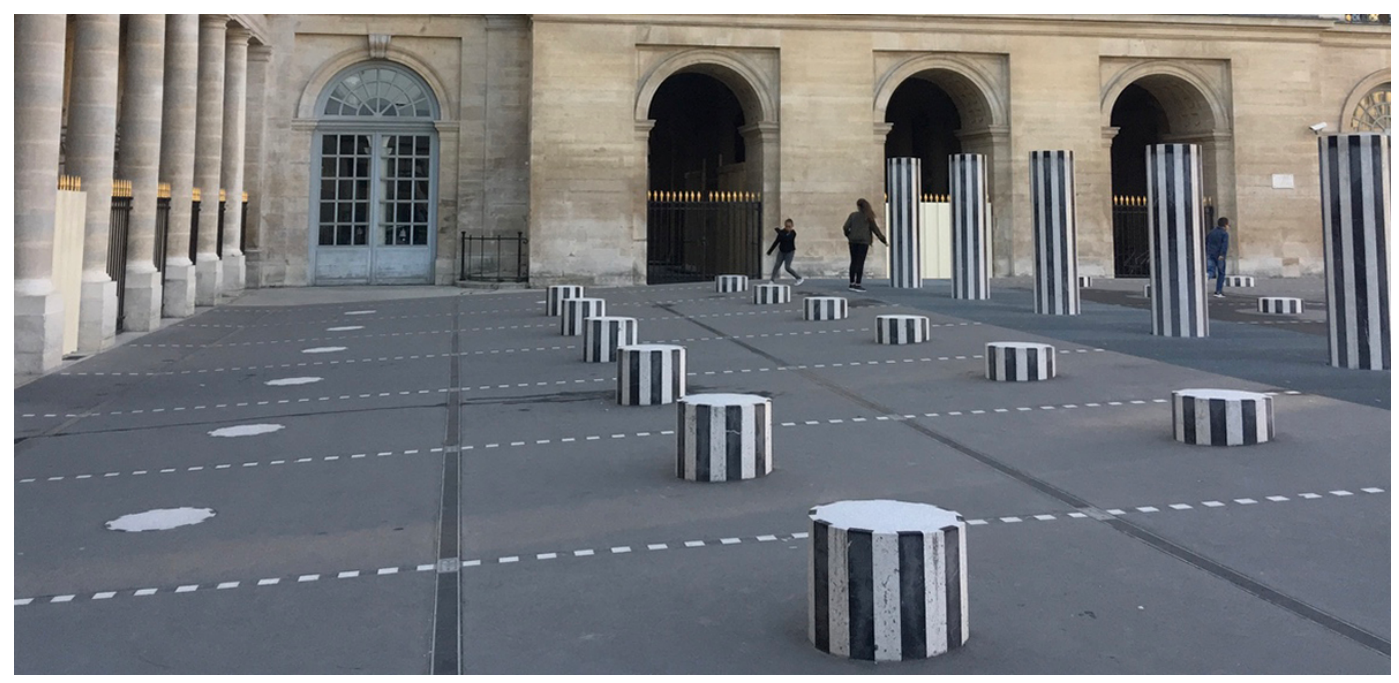

Fig. 3. Daniel Buren, Les deux Plateaux, 1986. Registro fotográfico de la obra, Palais Royal, París, Francia. Fuente imagen: (C) Archivo Rodrigo Bruna

Complementando las definiciones dadas al término in situ, el catedrático español Josu Larrañaga nos propone dos formas de abordar el espacio a partir de la práctica instalativa.

Básicamente podemos decir que la instalación ocupa un espacio en el que se adecua una propuesta sin que las condiciones de uno y otro interfieran, mientras que en otra actúa sobre él lo que es lo mismo se le incorpora a la obra con su historia, referencias 
y características formales, o incluso aquella está proyectada para hablar de y con la arquitectura que la acoge. (55).

Es en esta última opción propuesta por Larrañaga que se inscribe la instalación del artista francés Christian Boltanski (1944-2021), titulada Migrantes (2012) ${ }^{6}$. Mediante esta obra Boltanski no solo ocupa un lugar específico (museo), sino también actúa sobre la propia historia que este preserva. El artista propuso una obra que recoge la historia y los relatos del lugar, mediante elementos sonoros, lumínicos y objetuales. La atmósfera del lugar se inunda de una especie de bruma que atenúa la visibilidad, doscientas voces que en diversos idiomas inundan el espacio con nombres, edades, profesiones, lugares de procedencia y fecha de arribo, son los propios inmigrantes que reclaman una presencia ya olvidada. Por su parte, en una de las salas nos encontramos con un grupo de camas ordenadas y envueltas enigmáticamente con polietileno transparente. Cada una de las camas tiene en su interior un foco de luz blanca que simbólicamente restituye la presencia de los cuerpos en este lugar (figura 4).

El recorrido por el espacio se ve, finalmente interrumpido por un conjunto de abrigos que cuelgan desde el techo interpelando el tránsito de los espectadores e instalando relaciones asociativas vinculadas a la ausencia, desaparición y memoria.

A través de esta obra, Christian Boltanski reúne en un mismo espacio ficción y realidad con el objetivo de reconstruir la historia de un lugar a través de las memorias que lo habitan. Esta forma de actuar en el espacio nos permite vislumbrar posibles relaciones que se generan entre las artes visuales y las artes escénicas desde la práctica del site-specific.

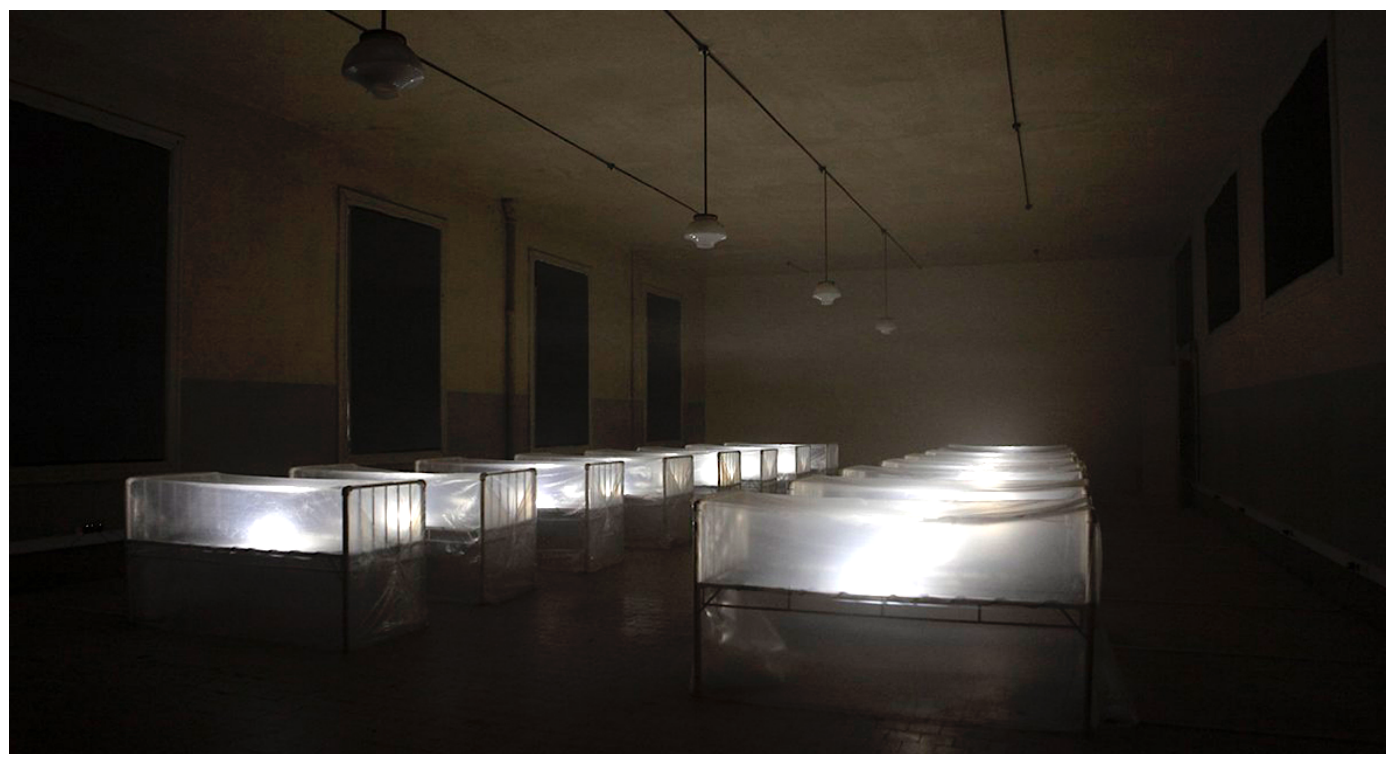

Fig. 4. Christian Boltanski, Migrantes, 2012. Registro fotográfico de la obra, Museo de Inmigrantes, Buenos Aires, Argentina. Fuente imagen: http://boltanskibsas.untref.edu.ar/php/proyecto/inauguracion-boltanski-buenos-aires/

${ }^{6}$ El Museo de la Inmigración se instaló en el antiguo Hotel de Inmigrantes, un espacio inaugurado en 1911 y que tuvo como objetivo albergar a los inmigrantes provenientes de Europa y de otras latitudes. 


\section{Site-specific y las artes escénicas}

A fines de los años 60 el director de teatro y teórico Richard Schechner da origen al llamado environmental theater, una práctica teatral no frontal que disuelve los límites entre espacio escénico y espectador ${ }^{7}$. Mediante esta modalidad teatral se apela a una experiencia envolvente que invade el espacio del espectador y amplía el área de acción de los actores, potenciando una mayor interacción entre los actores y el público. En atención a esta práctica Schechner afirma:

Teatralmente, El ambiente puede concebirse de dos maneras distintas. En primer lugar, lo que uno puede hacer con y en un espacio. En segundo lugar, es la aceptación de un espacio dado. En el primer caso se crea un ambiente mediante la transformación de un espacio; en el segundo caso, se trata con un ambiente ya existente, iniciando un diálogo escénico con un espacio. En el ambiente creado es la propia representación la que, en cierto sentido, establece la colocación y el comportamiento de los espectadores; mientras que en el ambiental tratado la situación más fluida permite algunas veces controlar la representación y a los espectadores. $\left(\right.$ Schechner párr. 2) ${ }^{8}$.

Interesante de analizar, a partir de la cita, es el hecho de cómo el teatro ambiental asume el espacio, por un lado, como una entidad surgida de la trasformación y por otro lado como una entidad dada que se abre al diálogo escénico. Esta última modalidad presenta, para Schechner, ciertas características que deben ser consideradas al momento de ser utilizadas por el teatro ambiental. Al respecto el autor comenta:

(1) Teniendo en cuenta los elementos de un espacio arquitectónico, cualidades de textura, acústicas y demás, estas deben ser exploradas y usadas, no disfrazadas; (2) el

\footnotetext{
${ }^{7}$ En 1973 Richard Schechner escribe su texto "Seis Axiomas para el Teatro ambiental" y establece los principios que rigen esta práctica teatral.

${ }^{8}$ La traducción de la cita es mía: Theatrically, environment can be understood in two different ways. First, there is what one can do with and in a space. Secondly, there is the acceptance of a given space. In the first case one creates an environment by transforming a space; in the second case, one negotiates with an environment, engaging in a scenic dialog with a space. In the created environment the performance in some sense engineers the arrangement and behavior of the spectators; in a negotiated environment a more fluid situation leads sometimes to the performance being controlled by the spectators.
} 
orden casual del espacio debe ser aceptado; (3) la función de los decorados, si se utilizan, debe ser la de interpretar el espacio, y no la de camuflarlo o transformarlo; (4) la posibilidad de que los espectadores creen improvisada e inesperadamente nuevas situaciones espaciales debe tenerse siempre en cuenta. (Schechner xxxiii-xxxiv) ${ }^{9}$.

A partir de estos espacios encontrados, Schechner deja definida una práctica que releva el uso formal y simbólico de los espacios, iniciando con ello nuevos caminos investigativos en torno a las posibilidades que otorgan los lugares no solo a la construcción de una escena sino también a la construcción de un cuerpo dramático. Ese es el caso de la obra Mother courage and her children ${ }^{10}$ (1975) obra realizada por la compañía The Performance Group y dirigida por Richard Schechner y presentada en el Performing Garage del Soho en Nueva York. La pieza descentró el foco de la acción teatral, generando múltiples puntos de vistas que activaron el rol del espectador, dinamizando el espacio y la dramaturgia propuesta. Del mismo modo podemos señalar que la obra no buscó "disfrazar" el espacio, sino más bien presentarlo, potenciando sus posibilidades escénicas (figura 5).

\footnotetext{
${ }^{9}$ La traducción de la cita es mía: (1) the given elements of a space-its architecture, textural qualities, acoustics, and so on-are to be explored and used, not disguised; (2) the random ordering of space or spaces is valid; (3) the function of scenery, if it is used at all, is to understand, not disguise or transform, the space; (4) the spectators may suddenly and unexpectedly create new spatial possibilities.

${ }^{10}$ La obra fue escrita por Bertolt Brecht en 1939 y está ambientada durante la Guerra de los Treinta Años (16181648). A través de esta pieza el autor alemán propone una reflexión sobre el ascenso del régimen nazi y sobre los efectos devastadores de la guerra.
} 


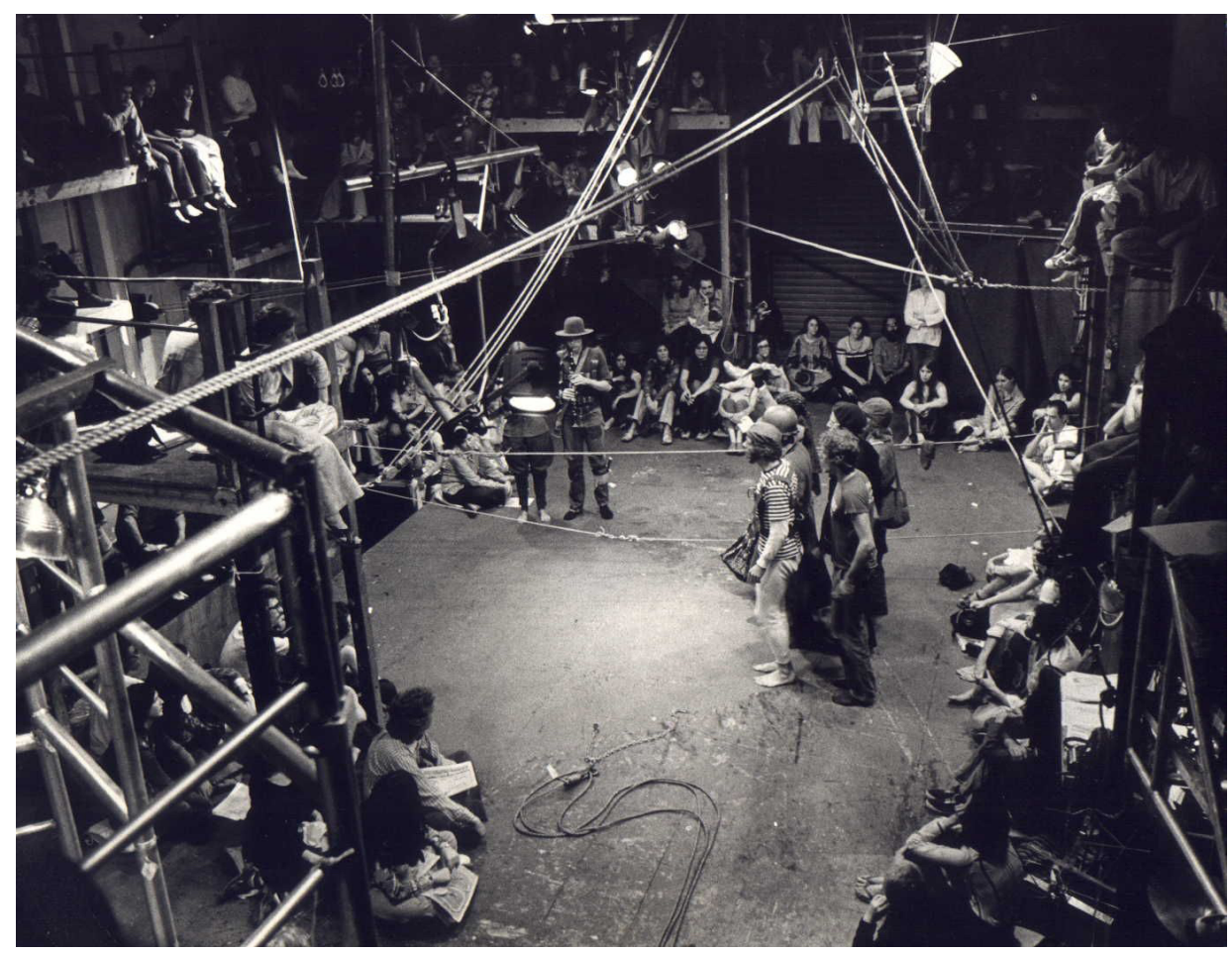

Fig. 5. The Performance Group, Mother courage and her children, 1975. Registro fotográfico de la obra, Wooster Street in Soho, New York, Estados Unidos.

Fuente imagen: http://www.rojo.uconn.edu/environmental/mothercourage1.jpg

A mediados de los años noventa el teórico alemán Hans-Thies Lehmann retoma el ideario planteado por Schechner y le da una nueva lectura a partir de la noción site-specific theatre ${ }^{11} \mathrm{o}$ como él lo denominó theatre on location:

Por un lado, el lugar específico de actuación puede ser utilizado tal cual: los actores actúan simplemente entre las máquinas de una fábrica y ante los utensilios con lo que se encuentran; actúan en naves de reparación de ferrocarriles y el público se encuentra asimismo situado simplemente en el lugar - puede haber sillas o palcos a su disposición sin que se altere el carácter básico de la espacialidad como escena-. (Lehmann 296).

\footnotetext{
${ }^{11}$ Una de las primeras compañías que se vinculó a las prácticas del site specific theatre fue la compañía galesa Brith Gof, grupo fundado en 1981 por Mike Pearson y Lis Hughes Jones.
} 
En estos lugares específicos, actores y espectadores participan de una experiencia conjunta cargada de historias y relatos. Caso interesante de analizar dentro de esta modalidad es la compañía Toneelgroep Hollandia ${ }^{12}$, grupo pionero en desarrollar la modalidad del site specific theatre en Holanda. Sus locaciones responden a espacios reales (depósito de chatarra, fábrica, esclusa, entre otros espacios) que desde su condición formal y simbólica determinaron la propia dramaturgia creada por el grupo. Es el caso de la pieza Körper Brennen (1991) la cual se desarrolló en el Fort Kijduin, un fuerte napoleónico (1713) ocupado por los soldados alemanes durante la Segunda Guerra Mundial. La pieza da cuenta de la relación de tres soldados cuyas pasiones e impulsos los lleva al desamparo y la autodestrucción. La memoria del espacio sitúa los diálogos y potencia las experiencias vivenciadas por los espectadores (figura 6).

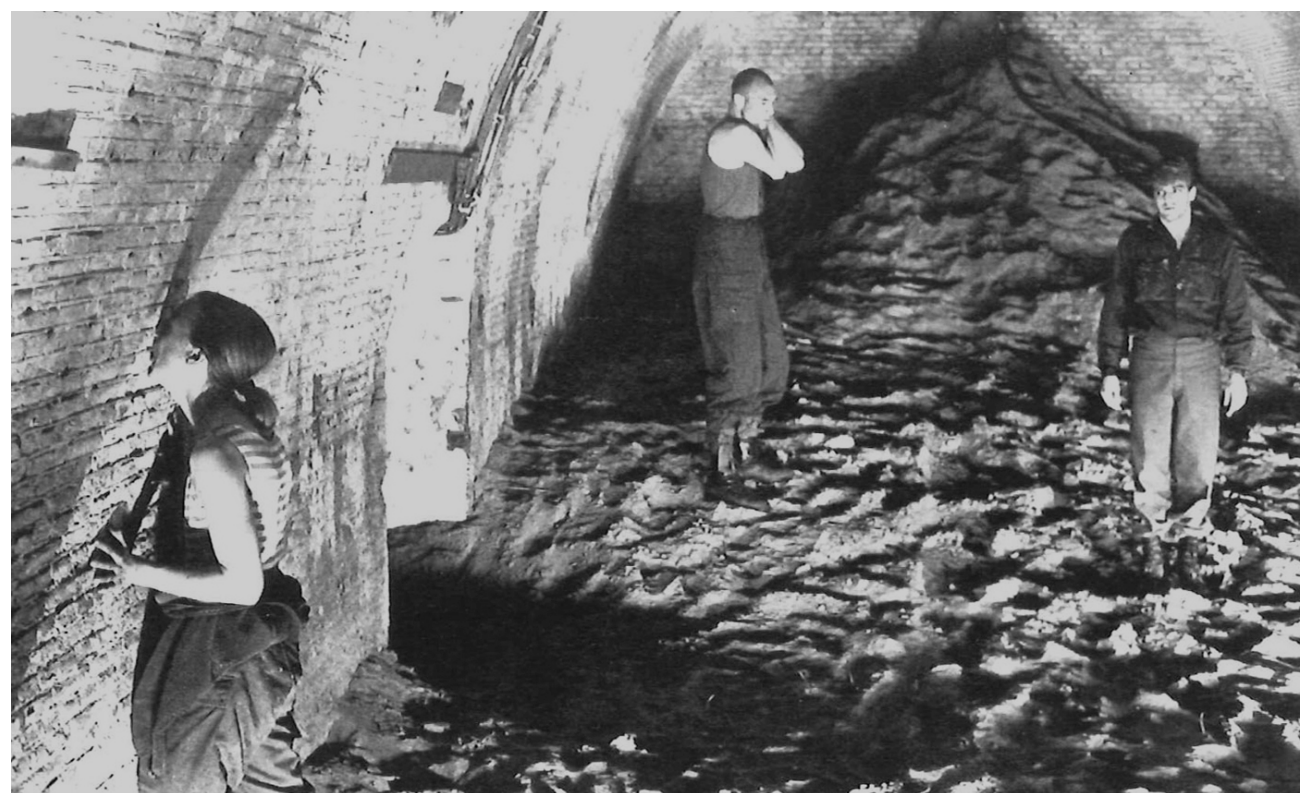

Fig. 6. Toneelgroep Hollandia, Körper Brennen, 1991. Registro fotográfico de la obra, Fort Kijduin, Den Helder, Países Bajos. Fuente imagen: https://e-tcetera.be/wp-content/uploads/1991/09/1991-09_jg9_nr35_01.jpg

El site-specific theatre asume los lugares desde su condición de estímulo creativo, donde el paisaje, la arquitectura, la historia y la memoria se hacen presentes, incorporando nuevos elementos a la dramaturgia y al quehacer escénico. En definitiva, esta modalidad del teatro contemporáneo busca no solo ocupar un lugar específico, sino que también actuar con él a través de un diálogo que impacta en la dramaturgia y en la propia experiencia corporal del espectador.

\section{Reflexiones finales}

Los procesos exploratorios desarrollados a fines de la década de los sesenta dieron origen a nuevas prácticas y procesos de trabajo en el campo de las artes escénicas y visuales. El surgimiento de modalidades como el site specific y el teatro ambiental permitieron una toma de conciencia de la noción de lugar y una emancipación del rol del espectador.

Bajo este contexto, la compañía Teatro da Vertigem retoma esta tradición explorando las posibilidades que otorga el site-specific. En correspondencia con esta modalidad, la compañía

\footnotetext{
${ }^{12}$ El Toneelgroep Hollandia fue creado en 1985 por el director teatral Johan Simons y por el músico Paul Koek. El grupo surge de la fusión de dos compañías regionales: Acht Oktober (1976) y el Regio Theatre (1978).
} 
construye un discurso que pone en valor las cualidades simbólicas, históricas y formales de los espacios que ocupa. Al respecto, podemos afirmar que gran parte de las producciones del Teatro da Vertigem responden a un aquí y un ahora que reivindica y visibiliza la ciudad como soporte de producción. Mediante este actuar la obra adquiere una especificidad donde las relaciones de tiempo y espacio responden a una dramaturgia situada y de carácter colaborativo.

A través de las obras revisadas podemos constatar que existe un interés, por parte de la compañía, de situarse en un espacio intermedio entre lo escénico y visual, hecho que le permite a la compañía pensar lo interdisciplinario como un espacio que tensiona el canon disciplinar y amplía las prácticas artísticas - investigativas.

Finalmente podemos afirmar que la noción de site-specific, en el discurso de la compañía Teatro da Vertigem, se transforma en un modo de entender y escenificar la memoria de los lugares a partir de una dramaturgia situada, donde actores y espectadores se hacen parte de una experiencia teatral envolvente e integral.

\section{Bibliografía}

Araújo, Antônio. "Dramaturgia en el colectivo: Intervenciones en espacios urbanos y «proceso colaborativo» en el Teatro da Vertigem." Repensar la dramaturgia: errancia y transformación. Eds. Belllisco, Manuel, Cifuentes, M. José y Écija, Amparo. Murcia, España: CENDEAC, 2011. 220-241. Impreso.

Augé, Marc. Los no lugares. Espacios del anonimato. Barcelona, España: Gedisa, 2008. Impreso. García, Silvana. "Los asentamientos urbanos del Teatro da Vertigem." Utopías de la proximidad en el contexto de la globalización: la creación escénica en Iberoamérica. Ed. Bernal, Oscar. Cuenca, España: Ediciones de la Universidad de Castilla-La Mancha, 2010. 27-45. Impreso.

--------“Apocalipsis 1,11: la redención por el teatro.” Archivo Artea. 2000. s.p. Web. 19 Abr. 2021.

Kwon, Miwon. One place after another. Site-specific art and locational identity. Cambridge: The MIT Press, 2004. Impreso.

Larrañaga, Josu. Instalaciones. Donostia-San Sebastián, España: Nerea, 2001. Impreso.

Lehmann, Hans-Thies. Teatro posdrámatico. Murcia: CENDEAC, 2013. Impreso.

Maderuelo, Javier. El espacio raptado. Barcelona: Grijalbo, 1993. Impreso.

Schechner, Richard. Environmental Theater. New York: Applause, 1994. Impreso.

Recibido: 31 de Mayo de 2021

Aceptado: 21 de Julio de 2021 